Baltic Astronomy, vol. 7, 329-339, 1998.

\title{
THE WET INSTRUMENTATION: FIVE YEARS OF THE VILNIUS GROUP EXPERIENCE
}

\author{
R. Kalytis
}

Institute of Material Research and Applied Sciences, Vilnius University, Čiurlionio 29, Vilnius 2009, Lithuania

Received March 1, 1998.

\begin{abstract}
Five year experience of the Whole Earth Telescope (WET) group of the Vilnius University in development and construction of instrumentation for the WET project is considered. The concept of design and fabrication of the WET photometric equipment is presented. Several components of the equipment as well as the complete photometers designed and made by the Vilnius group are described in brief.
\end{abstract}

Key words: instrumentation: photometers

\section{INTRODUCTION}

The instrumental group at the Astronomical Observatory of the Vilnius University joined the WET in 1992. We considered that our experience in developing and constructing of photometric instrumentation, acquired during accomplishment of the orders of military and aero-space industry companies of the former Soviet Union, could be also useful for the WET project. We started from the design and fabrication of an amplifier-discriminator - the smallest, but important component of any photometer. Almost ten versions of amplifierdiscriminators had been made during three years until the last one, F 316 A, was accepted in 1995 as a standard component of the WET photometer. After that the WET authorities gained some confidence in our possibilities. Some other components, as well as the complete three-channel photometers, have been designed and made for several WET groups since 1995. 


\section{OUR CONCEPT OF DESIGN}

Our concept of design, already discussed at the WET workshops (Kalytis \& Meištas 1995) and based on the minimal use of industrially made components in astrophotometers, has proven its validity. We think that for the WET photometer, which is a very specific instrument, optimized solutions of optical, mechanical and electronic design should be used which could ensure not only its necessary technical specifications but also comfortable operational properties. The use of the "off the shelf" components sometimes causes a certain sacrifice in optimality of the solutions.

\section{LIST OF THE PHOTOMETRIC EQUIPMENT DESIGNED}

During the last five years the main components of the WET high-speed three-channel photometers have been designed and made (Kalytis et al. 1993, 1996, Kalytis \& Meištas 1995). They include the light detecting units called "photoelectric heads" which contain photomultiplier (PMT) housings, PMT cooling systems, high voltage (HV) dividers, amplifier-discriminators (A-Ds), filter setting systems, computer interfaces and power supplies (Table 1). Several modernizations of the "Pancake" portable photometer (Meištas 1993) have been made during this time, too. In 1996 we started to design and to fabricate the complete photometers. The first one was the NPL (Nather-Polish-Lithuanian) photometer designed and made for the Suhora Astronomical Observatory, Poland.

The photometric instruments listed in Table 1 were designed for the specific WET or other needs. This equipment can be also suitable for a wider astronomical application, especially for observations of variable stars. Such components as HV dividers, A-Ds, filter setting systems, power supplies, computer interfaces and others can be used in all types of astrophotometers. The photometric instrumentation designed is comfortable to use in expeditions to the remote sites.

\section{AMPLIFIER-DISCRIMINATORS OF SERIES F 300}

Over ten models of amplifier-discriminators of small size, called A-Ds of the series F 300, have been designed during the last five years (Kalytis et al. 1993, 1996, Kalytis \& Meištas 1995). F 316A is the last and probably the final version of an amplifier-discriminator suitable for the standard WET photometer. It is fully approved 
Table 1. List of the photometric equipment designed by the Vilnius WET group in 1992-1997.

\begin{tabular}{|c|c|c|}
\hline Type of device & Model & Main specifications \\
\hline High voltage dividers & $\begin{array}{l}\text { D } 303 \\
\text { D } 304\end{array}$ & $\begin{array}{l}\text { Both: grounded minus, set for the Hamamatsu } \\
\text { PMTs of } 14 \mathrm{~mm} \text { diameter (R 647-04 or like it) }\end{array}$ \\
\hline Amplifier-discriminators & $\begin{array}{l}\text { F } 310 \\
\text { F } 316 \text { A } \\
\text { F } 318 \\
\text { F } 320\end{array}$ & $\begin{array}{l}\text { PPR }-8 \mathrm{~ns} \text {, sensitivity }-100 \mu \mathrm{V} \\
\text { PPR }-22 \mathrm{~ns} \text {, sensitivity }-130 \mu \mathrm{V} \\
\text { PPR }-8 \mathrm{~ns} \text {, sensitivity }-150 \mu \mathrm{V} \\
\text { PPR }-6 \mathrm{~ns} \text {, sensitivity }-150 \mu \mathrm{V}\end{array}$ \\
\hline Filter setting systems & $\begin{array}{l}\text { FD } 301 \\
\text { FD } 306 \\
\text { FD 308-2 }\end{array}$ & $\begin{array}{l}\text { Dual wheel, } 5 \text { filters, full feedback } \\
\text { One wheel, } 5 \text { filters, full feedback } \\
\text { Dual wheel, } 5 \text { filters, full feedback }\end{array}$ \\
\hline Power supplies & $\begin{array}{l}\text { A } 304 \\
\text { A } 305 \\
\text { A } 306\end{array}$ & $\begin{array}{l}\mathrm{HV},+5 \mathrm{~V},+12 \mathrm{~V} \\
\mathrm{HV},+5 \mathrm{~V},+12 \mathrm{~V}, 4 \mathrm{~V} \\
\mathrm{HV},+5 \mathrm{~V},+12 \mathrm{~V}, 24 \mathrm{~V}, 10 \mathrm{~V}\end{array}$ \\
\hline Photoelectric heads & $\begin{array}{l}\text { FEG } 304 \\
\text { FEG } 306 \\
\text { FEG } 310\end{array}$ & $\begin{array}{l}\text { Spectral range } 250-1100 \mathrm{~nm} \text {, } \\
\text { Two-stage cooling system } \\
\text { Weight }-1.85 \mathrm{~kg} \\
\text { Dimensions - } 180 \times 110 \times 110 \mathrm{~mm} \\
\text { Spectral range } 250-900 \mathrm{~nm} \\
\text { Two-stage cooling system } \\
\text { Weight - } 1.50 \mathrm{~kg} \\
\text { Dimensions - } 160 \times 128 \times 110 \mathrm{~mm} \\
\text { Spectral range } 300-650 \mathrm{~nm}(\mathrm{R} 647 \mathrm{P}) \\
\text { or } 185-850 \mathrm{~nm}(\mathrm{R} 1463 \mathrm{P}) \\
\text { Two channels } \\
\text { One stage cooling system } \\
\text { Weight }-0.85 \mathrm{~kg} \\
\text { Dimensions }-110 \times 70 \times 65 \mathrm{~mm}\end{array}$ \\
\hline Computer interface & CCLA & $\begin{array}{l}\text { Microprocessor }-8032 \mathrm{AH} \text {, } \\
\text { Oscillator - } 12 \mathrm{MHz}(0.5 \mathrm{ppm}) \\
\text { Three counting channels }(125 \mathrm{MHz}) \\
\text { Filter wheel control }\end{array}$ \\
\hline Photometer & NPL & $\begin{array}{l}\text { Two units: NPL-1 and NPL-2 } \\
\text { Three channels }\end{array}$ \\
\hline
\end{tabular}

by E. R. Nather and other WET authorities. The main feature of all A-Ds of series F 300 is a successful solution of their mechanical construction. The construction of fully soldered case has allowed 
us to design not only a small-size amplifier, but also to achieve a high level of shielding. Electrical specifications of F 316A (Kalytis \& Meištas 1995) are fully compatible with those of modern PMTs and computer interfaces.

For photometers in which "one cable" (Kalytis \& Meištas 1995, Kalytis et al. 1997) systems will be used, the model F 318 is foreseen. It is very tempting to conduct the signal and HV into PMT's housing through the same cable. Now, when all electronic pieces, including amplifier-discriminators, power suppliers and computer interfaces, have become sufficiently small to place them close to the photometer, this way of wiring could be considered as very useful. Tests of such wiring have passed successfully and the divider of the type D 304 (Kalytis \& Meištas 1995) has been made for this purpose. The conduction of the signal and HV power supply through the same cable simplifies significantly the circuit of the divider and enables to diminish its dimensions. Moreover, this reduces the number of cables in the photometer by three times.

\section{SIMPLE AND CHEAP WAY TO ROTATE THE WHEEL OF FILTERS}

In attempting to improve the electrical and mechanical system for drive and control of the filter wheels in WET photometers, we developed a simple and cheap method of wheel rotation. It is based on the use of sine voltage power supply of step motors which are usually used for this purpose. We use the step mode of a step motor only for start, stop and maintaining. The move to the next position of the wheel is accomplished like in a synchronous $\mathrm{AC}$ motor, i.e. by using a sine voltage. We use the full feedback in order to get information on the exact position of the filter wheel. The control of the step motor becomes very simple and easily understandable in this case.

Filter setting systems of this series (Kalytis et al. 1997) utilize the main merits of step motors and avoids their imperfections which happen when using them in astrophotometers. Thus, such a system for filter setting has better specifications in comparison with the standard WET photometer where the pulse mode for driving of the step motors is used.

These merits are the following: 
(1) faster rotation of the wheel;

(2) uniform (soft) turn to the needed position; it means higher reliability of the system due to lower probability for the filters of getting loose due to shaking;

(3) significantly lower power consumption;

(4) lower utilization of the computer/interface resources for the control and its simplicity;

(5) full feedback in each filter position, which ensures a setting of the wheel in the necessary position and a possibility to receive information that this position has been reached;

(6) very simple construction and circuitry;

(7) very simple remote control from computer/interface or from a manual remote control desk.

\section{WHAT INTERFACE DO WE NEED?}

It has been stated during the WET workshops of 1995 and 1997 that the computer interface which is now in use in many of the WET groups needs redesigning.

In 1996 the Vilnius group redesigned this interface and made the card named CCLA (Chris Clemens-Luja-Ališauskas). However, this card has the same circuitry as the original C. Clemens' interface. Only drawing of PCB has been changed in this design.

The following imperfections and related problems have been found in the Clemens' design of three-channel computer interface for the WET:

(1) the third channel is added later on and in a different way than the first two channels;

(2) readout of channels is designed imperfectly, i.e. in consecutive order, which causes:

- time loss (about $0.4 \mu$ s per one integration time),

- phase shift (about $6 \mu \mathrm{s}$ ) of integration time between channels,

- artificial narrowing of the frequency range of counters up to $14 \mathrm{MHz}$ instead of $125 \mathrm{MHz}$ rated in the data sheets of the fast TTL used;

(3) problems of timing:

- integration time can be maintained with uncertainty of $1 \mu \mathrm{s}$ at least, even using a $1 \mathrm{kHz}$ accurate time signal,

- comparatively large minimum integration time (about $12 \mathrm{~ms}$ ),

- the use of the $1 \mathrm{~Hz}$ and $1 \mathrm{kHz}$ accurate time signals is not solved completely; 
(4) the use of a serial RS 232 port for the data sending to PC limits the possibilities of interface, especially in the case of extremely short integration times.

To eliminate these drawbacks and solve the problems mentioned we suggest the following changes:

(1) to use a simultaneous parallel read-out of all channels;

(2) to introduce the circuit of frequency corrector;

(3) to use a parallel port or other faster port for the data transfer to $\mathrm{PC}$ or to use both the parallel and serial ports;

(4) to use the EPROM program only for initialization and loading the working programs from PC; this modification is still a matter for discussion.

These changes would allow one to make the interface suitable not only for WET, but also for general-purpose applications.

The main merits of such a design are seen as the following:

(1) all channels start the signal integration at the same time, and we have exactly the same duration of integration time in each channel;

(2) all problems of timing would be solved; in addition, a new possibility appears: in this case we have the frequency-correction and accurate integration time with only a $1 \mathrm{~Hz}$ accurate time signal, i.e. without the oscillator of high stability which could be saved only for the exceptional cases when the time signal disappears;

(3) the ability of counting up to $125 \mathrm{MHz}$ would be fully employed; time.

(4) a possibility appears to get shorter (up to $20 \mu \mathrm{s}$ ) integration

\section{PHOTOELECTRIC HEADS OF SERIES FEG 300}

PMTs used in the WET photometers do not need cooling. However, for general-purpose photometers, in which multialkali PMTs are used, cooling is rather necessary. Thus the experience we have accumulated during designing and fabricating the broad-band detector units (photoelectric heads) for ecological needs or for stellar spectrophotometry has become quite useful now. The photoelectric heads (PH) FEG 304 and FEG 306 were made in 1994-1996. In 1997, a new PH, FEG 310, was designed, made and tested. FEG 310 is designed for the three-channel high-speed photometer TTCP of the Capodimonte Observatory, Naples, Italy. 
The WET instrumentation: the Vilnius group experience

Table 2. Main specifications of the photoelectric heads FEG 306 and FEG 310.

\begin{tabular}{lll}
\hline & FEG 306 & FEG 310 \\
\hline Spectral range & 250 to $1060 \mathrm{~nm}$ & $\begin{array}{l}300 \text { to } 650 \mathrm{~nm} \text { (R647P); } \\
185 \text { to } 850 \mathrm{~nm} \text { (R1463P) }\end{array}$ \\
$\begin{array}{l}\text { Maximum error } \\
\text { of the light registration }\end{array}$ & $\leq 1.2 \%$ & $\leq 1.1 \%$ \\
Sensitivity variations & $\leq 2 \%$ per 10 hours & $\leq 0.5 \%$ per 10 hours \\
Dead time & $20 \pm 2 \mathrm{~ns}$ & $22 \pm 2 \mathrm{~ns}$ \\
Output pulses & correspond to fast TTL & correspond to fast TTL \\
Temperature of PMT & $-35^{\circ} \mathrm{C}$ and $-50^{\circ} \mathrm{C}$ & $-5^{\circ} \mathrm{C}$ and $-15^{\circ} \mathrm{C}$ \\
The system of PMT cooling & $\begin{array}{l}\text { two-stage thermoelectric } \\
\text { cooler }\end{array}$ & $\begin{array}{l}\text { one-stage thermoelectric } \\
\text { cooler }\end{array}$ \\
& $\begin{array}{l}180 \times 110 \times 110 \mathrm{~mm} \\
1.50 \mathrm{~kg}\end{array}$ & $\begin{array}{l}110 \times 70 \times 65 \mathrm{~mm} \\
0.85 \mathrm{~kg}\end{array}$ \\
\hline $\begin{array}{l}\text { Dimensions } \\
\text { Weight }\end{array}$ &
\end{tabular}

The PHs FEG 304 and FEG 306 have a very deep cooling (up to $-50^{\circ} \mathrm{C}$ ) because of the use of PMTs with GaAs and InGaAs photocathodes. In FEG 310, the requirements for cooling are not so strict, but it has more complicated size restrictions: the head has to be two-channel and the distance between the two heads (which determines the distance between the first and second channels) should be as small as possible.

In Table 2, the main specifications of the PHs FEG 306 and FEG 310 are presented for intercomparison.

A distinctive design of actively ventilated heat absorber of thermoelectric cooler in both PHs solved the problem of its effectiveness and weight. We avoided the necessity to use water for heat transfer.

\section{PHOTOMETERS}

\subsection{Introduction}

When developing separate components of photometric equipment, in 1993 we started to modernize the "Pancake" travelling pho- 
tometer (Meištas 1993). This three-channel photometer, initially designed by E. Meištas and J.-E. Solheim and fabricated at the Tromso University, later on became a training facility for the Vilnius WET group. It was used for checking new ideas and solutions and for testing the new components designed. During the last four years the "Pancake" has suffered three essential modernizations and more less important ones.

The idea of the flat three-channel photometer turned up as very fruitful. Joined with the nice idea of "miniphots " developed in Texas (Kleinman et al. 1996) this idea has allowed us to design and manufacture the NPL photometer for the Suhora observatory and to engage into the project of the TTCP photometer, the photometer for the Capodimonte Observatory (see Section 8.3).

\subsection{The NPL photometer}

A three-channel astrophotometer NPL was designed and made by the Vilnius WET group for the Suhora Observatory (see Section 3). The first unit NPL-1 was designed as a two-channel (for measuring of a target star and the sky) photometer. The separate one-channel unit NPL-2 was designed and made for measuring a comparison star. The main purpose of this design was to make a sufficiently small photometer which could be added to the existing two-channel photometer of the Suhora Observatory.

\subsubsection{Structure of the NPL}

The photometer consists of four main parts:

(1) two-channel unit or photometer NPL-1,

(2) one-channel unit or photometer NPL-2,

(3) electronic module FE 305 including three amplifier-discriminators of type F $316 \mathrm{~A}$,

(4) electronic unit for the filter setting system FD 308-2.

NPL-1 consists of the following modules:

(1) housing for two photomultipliers Hamamatsu R647 and two high-voltage dividers D 303,

(2) module of the shutter,

(3) filter wheel,

(4) microscope module,

(5) module of the apertures, 
(6) assembly for rotation and focusing of the photometer.

NPL-2 consists of the following modules:

(1) housing for PMT and HV divider,

(2) module of the shutter,

(3) filter wheel,

(4) microscope module,

(5) module of the apertures,

(6) assembly for finding the star.

The dual-wheel filter setting system FD 308-2 consists of two filter wheels on the axes of step motors in both units, NPL-1 and NPL-2, and a separate electronic unit for drive and control.

The electronic module FE 305 consists of two main parts: power supply A $306 \mathrm{M}$ and computer interface.

Main specifications of the two-channel photometer NPL-1 and one-channel photometer NPL-2 are given in Table 3.

\subsubsection{Electronic module FE 305}

The module FE 305 includes all electronic circuits necessary for the power supply and control of the NPL photometer, except of that for the filter setting system FD 308-2, which is designed as a separate unit. All circuits are placed into one box with the input and output connectors.

FE 305 consists of the power supply A 306M and the interface card. A 306M is a slightly modified power supply of the type A 306, designed especially for WET. The power supply is designed as a two-stage voltage changer. It is mounted on one-sided PCB in one of chambers of the electronic module. The power supply A 306M provides all voltages necessary for PMTs, amplifier-discriminators and interface card. These voltages are the following:

$+12 \mathrm{~V}$ for the amplifier-discriminators $\mathrm{F} 316 \mathrm{~A}$,

$+5 \mathrm{~V}$ for the interface card,

$\mathrm{HV}(+600 \mathrm{~V}$ to $+1100 \mathrm{~V})$ for the HV dividers D 303 (PMTs R 647-04).

The interface card is the latest version of the standard WET three-channel interface card (Clemens 1993). This card is designed to operate as a computer interface of the standard three-channel WET photometer. It ensures the data acquisition from three photon counting channels, the control of two filter wheels and the facilities of all timing circuits. If a suitable external time signal is available, 
Table 3. Main specifications of the NPL photometer.

\begin{tabular}{lll}
\hline Specifications & NPL-1 & NPL-2 \\
\hline Number of channels & 2 & 1 \\
Distance between the channels & $16 \mathrm{~mm}$ & - \\
Number of filters & five pairs $(5 \times 2)$ & five \\
Diameter of filters & $15.1 \mathrm{~mm}$ & $15.1 \mathrm{~mm}$ \\
Time of setting & & \\
of the next pair of filters & $0.25 \mathrm{~s}$ & $0.25 \mathrm{~s}$ \\
Number of apertures & six pairs $(6 \times 2)$ & $\mathrm{six}$ \\
Diameters of apertures & $0.35 ; 0.50 ; 0.7 ;$ & $0.35 ; 0.50 ; 0.7 ;$ \\
& $1.0 ; 1.4 ; 7.3 \mathrm{~mm}$ & $1.0 ; 1.4 ; 7.3 \mathrm{~mm}$ \\
Diameter of field apertures & $7.3 \mathrm{~mm}$ & $7.3 \mathrm{~mm}$ \\
Magnification of microscope & 25 & 25 \\
Diameter of the field of & $9 \mathrm{~mm}$ & $9 \mathrm{~mm}$ \\
microscope & & \\
Diameter of Fabri lenses & $14 \mathrm{~mm}$ & $14 \mathrm{~mm}$ \\
Focus length of Fabri lenses & $30 \mathrm{~mm}$ & $30 \mathrm{~mm}$ \\
Diameter of outcoming pupil & $2.5 \mathrm{~mm}$ & $2.5 \mathrm{~mm}$ \\
Dimensions of field for finding & - & ring $\left(\mathrm{d}_{1}=36 \mathrm{~mm}\right.$, \\
the comparison star & & $\left.\mathrm{d}_{2}=84 \mathrm{~mm}\right)$ \\
Dimensions of the photometer: & & $260 \mathrm{~mm}$ \\
height & $265 \pm 3 \mathrm{~mm}$ & $290 \mathrm{~mm}$ \\
diameter (including microscope) & $408 \mathrm{~mm}$ & $92 \mathrm{~mm}$ \\
diameter of the main frame & $96 \mathrm{~mm}$ & \\
\hline
\end{tabular}

the interface can process and use this signal for the accurate timing, too.

The electronic module FE 305 is designed as a box including two chambers separated by the inner plate which is joined with the front and back panels and covered by lids. Mounted on the front panel are three BNC connectors for inputs of the three channels.

\subsection{The TTCP photometer}

In 1997 our group started designing and fabricating a threechannel high-speed photometer for the $1.5 \mathrm{~m}$ telescope of the Capodimonte observatory. This photometer, named TTCP (Toppo Three Channel Photometer), should be the first photometer built by the Vilnius WET group, which corresponds to all requirements of the standard WET photometer (Kleinman et al. 1965). On the other hand, the solutions which we are going to realize in the design of the TTCP are result of our earlier experience and especially of our experience acquired during the last five years. 
The TTCP has to be a photometer with all three channels parallel to the main axis of the telescope. The second feature of TTCP is its suitability not only for WET, but also for usual multicolor photometry.

ACKNOWLEDGMENTS. All the instruments reported in this paper were designed and made by technical staff of the Astrophotometry Division of the Institute of Material Research and Applied Sciences of Vilnius University. The author recognizes the efforts of his colleagues R. Skipitis, V. Luja and D. Ališauskas to make all these designs possible. I would like to thank E. Meištas and J.Sperauskas for fruitful discussions and many advices. I am very grateful to J. E. Solheim for his initiative and help in introducing our team into the WET and for his patience in leading us throughout this work during the last five years. I recognize a careful attention of R. E. Nather and C. Clemens to our work. This work in 1996-1997 was partially supported by the Lithuanian State Foundation for Science and Studies and by the Lithuanian Ministry of Education and Science (1997).

\section{REFERENCES}

Clemens J. C. 1993 , Baltic Astronomy, 2, 501

Kalytis R., Skipitis R., Karaliūnas A., Dzindzelèta B. 1993, Baltic

Astronomy, 2, 504

Kalytis R., Meištas E. 1995, Baltic Astronomy, 4, 497

Kalytis R., Skipitis R., Luja V., Ališauskas D., Meištas E. 1996, Baltic Astronomy, 5, 579

Kalytis R., Skipitis R., Luja V., Ališauskas D., Meištas E. 1997, in Optical Telescopes of Today and Tomorrow: Following in the Direction of Tycho Brahe, ed. A. Ardeberg, Proc. SPIE, 2871, 1272

Kleinman S. J., Nather R. E., Philips T. 1996, PASP, 108, 356

Meištas E. 1993, Baltic Astronomy, 2, 498 
